\title{
Investigating the Extent to Which Personality Traits and Demographics Affect Job Satisfaction
}

\author{
Muhammad Sajid Saeed \\ Glasgow Caledonian University \\ E-mail: Msaeed14@caledonian.ac.uk
}

Received: May 25, 2016 Accepted: May 30, 2016 Published: June 5, 2016

doi:10.5296/bmh.v4i1.9535

URL: http://dx.doi.org/10.5296/bmh.v4i1.9535

\begin{abstract}
The primary concern of this paper is to investigate the extent to which three variables (i.e., personality traits, demographic variables, and job satisfaction) are interrelated with each other and what effect they have on each other in relation to the UK retail sector. The four different types of retail stores i.e., Tesco, Primark, Ikea and WH Smith were selected for survey purpose to minimise the class biasness. Total 300 close-ended questionnaires were distributed and 220 responses were obtained. The findings reveal that "Neuroticism" is negatively associated with job satisfaction as well as with "Extraversion". However, it is positively correlated with other three personality groups including "Agreeableness", "Conscientious", and "Openness". On the other hand, "Openness to experience" has a negative relationship with "Agreeableness". It is also found from the ranking analysis that employees with "Agreeableness" and "Conscientiousness" personalities are more successful in their career and consequently they are more satisfied with their jobs.
\end{abstract}

Keywords: Personality traits, Five-factor model, Job satisfaction, Extraversion, Agreeableness, Neuroticism, Conscientious, Openness to experience 


\section{Introduction}

Today, employee job satisfaction is a vital and one of the most common matters for many firms around the world. In this regard, employers play an imperative role to meet the requirements of the employees and keeping their morale high in order to achieve the best level of job satisfaction that can result in better performance of the firm.

In the last 20 years, great level of attention is given to investigating various aspects of five-factor model that consists of different personality characteristics such as Extraversion, Agreeableness, Conscientious, Neuroticism, and Openness. Similarly, a number of researches have been conducted in the context of finding relationships between personality traits and job satisfaction including self-esteem (La Sala et al., 2014) employee self-efficiency belief (Caprara et al., 2011) neuroticism (Shadel et al., 2004) and locus of control (Holland et al., 2010; Zitny \& Halama, 2011). But the relationship between personality traits and job satisfaction in the context of the UK retail sector has not received considerable attention of the researcher's community from the past two decades (Broadbridge et al., 2007; Whysall et al., 2009; Furnham et al., 2009). Some studies also reported the associations between demographic variables (age, gender, experience, and education) and job satisfaction but again no or very few studies have been conducted in the perspective of the UK retail sector (Hsieh, 2011; Celia, 2012).

Based on the literature gap identified above, the primary concern of this research is to fill this gap by investigating the issue that to what extent three variables (i.e., personality traits, demographic variables, and job satisfaction) are interrelated and have an effect on each other in relation to the UK retail sector. It is important to address this issue at this time when employee turnover in the UK retail industry has been increased rapidly and many graduate and post graduate students work temporarily in the retail stores and have tendency to leave their jobs due to dissatisfaction (Broadbridge et al., 2007; Whysall et al., 2009).

Hence, the core objective of this study is to investigate to what extent personality characteristics and demographic variables can affect job satisfaction in the UK retail sector. In this regard, it is important to identify the relationships between job satisfaction and five individual personality characteristics such as Extraversion, Agreeableness, Conscientious, Neuroticism, and Openness. In addition, this paper also discovers the consequence of employee's demographic factors on job satisfaction in the UK retail sector. As a matter of fact, two following research hypotheses are set in this study.

H1: Except Neuroticism, other individual personality characteristics of employees in retail sector are significantly correlated with job satisfaction

H2: There is a significant relationship between job satisfaction and employee demographics

\section{Literature Review}

\subsection{Job Satisfaction and Demographic Factors}

Kermani (2013) defined job satisfaction as "a pleasurable positive emotional state resulting from the appraisal of one's job or job experiences” (p. 104). 
Job satisfaction largely relies upon demographic factors such as age, sex, marital status, tenure, education, and ranks etc. Bashir et al. (2011) reported that numerous demographic variables are imperative predictors of job satisfaction. Therefore, demographic factors must be considered and thoroughly understood to determine job satisfaction or dissatisfaction of workers. Herzberg discovered numerous attributes of satisfied or dissatisfied employees (Scott et al., 2005). According to them, the morale of an employee is high when he/she starts a new job but with the passage of time the morale decreases to some or great extent depending on the job conditions and environment. Furthermore, the morale remains at a relatively low level once an employee reaches late twenties or early thirties (Scott et al., 2005). However, job satisfaction level after the thirties starts to increase and continue throughout the remaining career of an employee. Employees who start their careers with high morale experience a considerable decline in the first year which remains low for upcoming years. Then as tenure rises, the job satisfaction level tends to increase as well.

\subsection{Job Satisfaction and Personality Traits}

The five-factor model of personality characteristics illustrates that the personality of a human being is composed of five self-determining aspects which provide a considerable and a comprehensive catalogue for reassessing and re-evaluating the differences in the personalities (Eswaran et al., 2011). McDougall (2016) generally classifies personality traits into five distinctive elements such as disposition, intellect, character, temper, and temperament. But most of the researchers are collectively agreed to the point that personality traits are captured by five secondary factors such as extraversion, agreeableness, neuroticism, conscientiousness, and openness to experience.

The influence of personality traits on job satisfaction is an ongoing debate in the literature of management and psychology. A number of researches have been conducted in the context of finding relationships between personality traits and job satisfaction but still the understanding of the influence of personality on job satisfaction is unclear particularly in the retail sector context (Broadbridge et al., 2007; Whysall et al., 2009; Furnham et al., 2009). Given the robustness of big five-factor model of personality and its significance in explaining personality features, the following subsections portray the links between job satisfaction and five personality traits such as extraversion, agreeableness, conscientiousness, neuroticism, and openness to experience.

\subsection{Link between Job Satisfaction and Personality Traits}

\subsubsection{Extraversion}

People with extraversion characteristics are usually active, companionable, self-confident, outgoing, talkative, energetic, gregarious, and social. In addition, extraverts are dedicated to be impulsive, chatty, and spontaneous (McCrae \& Allik, 2012). Extraversion trait is considered as an outcome of difference in neurological and physiological mechanisms of human beings (Ashton, 2013). In contrast to introverts, extravert people react more affectively.

The comprehensive studies of Judge et al. (2002) have great significance in the literature of 
management in relation to finding the correlations between job satisfaction and personality traits. According to them, extraversion is positively and significantly correlated with job satisfaction. They estimated correlation up to 0.25 and a statistically significant beta regression coefficient.

\subsubsection{Agreeableness}

People with agreeableness traits are usually kind, affectionate, trustworthy, courteous, and cooperative (Judge et al., 2002). Agreeableness requires a pleasant and participative relationship with others. In order to analyze agreeableness on the societal level, it is found that this characteristic of an individual is significantly associated with communism and collectivism (Vogt \& Lehar, 2009). Persons with agreeableness features are more compromising, accommodating, and sensitive to others and prefer to stay away from arguments and conflicts. Caprara et al. (2006) also reported that individuals with agreeableness traits show conformity, traditional, and generous values.

A number of studies have shown that employees with agreeableness or collective orientation achieve higher job satisfaction in contrast to employees with other personality traits (Mihalcea, 2013). But in the opinion of Judge et al. (2002) it is true in case of the congenial teams. In fact during their meta-analysis, they estimated an accurate correlation of 0.17 between job satisfaction and agreeableness and a statistically insignificant beta regression coefficient. They assert that the correlations between job satisfaction and agreeableness are highly erratic across researches around the world as the confidence interval of $90 \%$ does not include zero.

\subsubsection{Conscientiousness}

People with Conscientiousness traits are normally well-organized, accountable, vigilant, determined, hardworking, thorough, systematized, attentive, diligent, comprehensive, and reliable (Judge et al., 2002). The conscientiousness feature of one's personality is a common predictor of job satisfaction and work performance. Conscientious individuals are risk averters, focused mind, and they can be easily differentiated on the basis of their positive and cautious thinking towards the risk. In regards to work, these individuals are short sighted and they prefer to achieve organizational goals by holding back personal goals. This ability makes them best related to job performance and job satisfaction (Judge \& Colquitt, 2004).

The studies of Judge et al. (2002) demonstrate that employees with conscientiousness behavior achieve high job satisfaction. During the meta-analysis, they estimated approximate correlation of 0.26 between job satisfaction and conscientiousness and a statistically significant beta regression coefficient. The process of transferring conscientiousness into job satisfaction is perceived acceptable all around the world without any exception of economy or culture.

\subsubsection{Neuroticism}

Like extraversion, neuroticism is also considered by the researchers as an outcome of difference in neurological and physiological mechanisms of human beings (Ashton, 2013). 
However, in contrast to extraversion, neuroticism is usually associated with individuals' emotional instability which often generates negativities. People with neuroticism traits are often moody, insecure, nervous, embarrassed, and anxious (Millon et al., 2012). As compared to other personality traits, neurotic individuals are not entitled to rewards in an organisational environment because of their unstable emotions and lack of temperament. In fact, they experience negative comments from colleagues and sometime face demotions.

The studies of Judge et al. (2002) illustrate that neurotic employees achieve low job satisfaction. During their meta-analysis, they estimated the correlation of -0.29 between job satisfaction and neuroticism and a statistically insignificant beta regression coefficient. The individuals with neuroticism traits are mostly not acceptable to most of the organization. A study is also reported high neuroticism level and thus lower job satisfaction (Sutin et al., 2009; Schultz \& Schultz, 2015).

\subsubsection{Openness to Experience}

People with openness to experience are often artistic, intellectual, creative and open minded, scientific, reflective, and have divergent thinking (Kerr \& McKay, 2013). Openness to experience usually has a dual effect on the individual's personality as it prompts individuals to have intense good and bad feelings at the same time (Kumar \& Backshi, 2010). In addition, the effect of openness on somebody's personality also allows him/her to respond affectively. This is the reason that to some extent, openness to experience tends to have a weak association with job satisfaction (Awadh \& Ismail, 2012).

In the opinion of Eswaran et al. (2011), openness to experience has a positive relationship with job satisfaction and job performance. They further assert that openness to experience is a valid predictor of the training proficiency criterion across occupations as the individuals with openness trait are more insightful, caring, and innovative. They are generally more optimistic in learning new things and from their own experiences as well as from the experiences of others. On the other hand, the perception of McCrae \& Allik (2012) is different about openness to experience. They believe that individuals with this trait are quite ambiguous, debatable, and complex to understand and thus more research is required to investigate this dimension of personality traits.

\section{Methodology}

\subsection{Research Design}

The researcher has chosen 'descriptive' research design as the study involves survey based investigation to explore links between job satisfaction and five individual personality traits such as Extraversion, Agreeableness, Conscientious, Neuroticism, and Openness. This study also encompasses 'review' research design to review the existing literature on personality traits and relationship among them. Descriptive research design is also relevant in this study because the researcher needs to address hypotheses that are established to support aim and objectives of the study (Bryman \& Bell, 2007). 


\subsection{Research Approach}

Both qualitative and quantitative approaches were selected in this study. The researcher employed qualitative approach subjectively to review five individual personality traits and also to discover the consequences of employee's demographic factors on job satisfaction. On the contrary, the quantitative approach was followed to address hypothesis of the study. The quantitative approach in this study embraces statistical analysis of survey responses of UK retail sector employees. The combination of both approaches helped the researcher to successfully achieve the aim and objectives of the research.

\subsection{Study Population}

The population of the study was the employees working in the UK retail sector. The four big retail stores were selected as sample for conducting survey. The attempt was made to select four different types of store to minimize the class biasness. These stores included: TESCO as a grocery store, Primark as clothing, Ikea as furniture/hardware, and WH Smith as newsagent/books. Furthermore, both females and males of different ages were surveyed in this study to reduce gender and age prejudices.

\subsection{Data Collection Method}

The primary data in this study was collected to for two reasons: (1) to find correlations between job satisfaction and personality characteristics; (2) to solve the dilemma how and to what extend demographic variables can influence job satisfaction. The descriptive survey method through close-ended questionnaires was used to collect primary data. Among two types of survey research (i.e., descriptive and analytical), descriptive survey is chosen because it informs the researchers about current situation. The close-ended questionnaire is preferred as it facilitates the researcher to easily record specific data for analysis purpose using various statistical methods (Bryman, 2008).

The questionnaire was designed in MS Word and clear guidance was provided to survey participants about how to fill the questionnaire. In addition, the employees from the UK retail sector were told about the purpose of this study (Saunders et al., 2009). The questions in the questionnaire were distributed among three main sections including personal information, job satisfaction section, and personality characteristics section. Total 300 questionnaires were personally distributed and administered by the researcher and this is the reason that the researcher received 220.

\subsection{Data Analysis}

The Relative Index (R.I) ranking technique was employed in this study to rank the items in the list of personality characteristics according to the responses of the survey participants (Doloi et al., 2011). The RI formula is as follows:

$$
r=\frac{\sum\left(1 a_{1}+2 a_{2}+3 a_{3}+4 a_{4}+5 a_{5}\right)}{5\left(a_{1}+a_{2}+a_{3}+a_{4}+a_{5}\right)}
$$




\section{Macrothink}

Moreover, the correlation analysis between all personality groups was conducted through SPSS where null hypothesis $r=0$ and alternative hypothesis $r \neq 0$ were assumed. In this study, the null hypothesis indicates no correlation between group variables and alternative hypothesis represents existence of negative/positive correlations. The correlations are calculated using Karl Pearson's (Jackson, 2011) formula stated as follows:

$$
r=\frac{\sum(x-\bar{x})(y-\bar{y})}{\sqrt{\sum(x-\bar{x})^{2}-\sum(y-\bar{y})^{2}}}
$$

The result of correlation coefficient ( $\mathrm{r}$ ) ranges between -1 and +1 which shows negative or positive relationships respectively.

\section{Results}

\subsection{Demographics}

Total 300 questionnaires were personally handed over among UK retail sector employees and 220 were returned. This indicates $73 \%$ contribution to the study where 53\% males and $47 \%$ females participated to the study. It was discovered that a higher percentage of employees between 18 and 25 ages work in retail store followed by people aged between 26 and 30 ages. It is interesting to know that employees above 40 years are reluctant to work in the retail sector. A high number of employees were found with undergraduate studies followed by postgraduate and diploma. Moreover, 30\% employees were holding undergraduate degrees while 28\% employees have completed their GCSE (General Certificate of Secondary Education).It was also found that a majority of employees (49\%) had just 1 to 5 years of experience. $25 \%$ employees were found with the experience between 6 and 10 years whereas $17 \%$ employees were new with less than 12 months experience.

\subsection{Ranking Analysis}

Based on the Big Five model of personality characteristics, 44 personality traits were included in the questionnaire and respondents were asked to rate themselves according to their thinking what they are. The respondents marked appropriate options as per following scale. 1- Strongly disagree, 2- Disagree, 3- Neutral, 4- Agree, and 5- Strongly agree.

The responses of the survey participants were recorded and analyzed through R.I. formula. Table 1 demonstrates the ranking results. The highest scores of personality characteristics under Agreeableness and Conscientiousness categories illustrate more job satisfaction of employees as they are more flexible and compromising in all types of working environment. 
Table 1. Ranking analysis of personality traits

\begin{tabular}{|c|c|c|c|c|}
\hline ID & Category & Personality Characteristics & R.I. & Rank \\
\hline $\mathrm{P} 22$ & Agreeableness & Is generally trusting & 85.27 & 1 \\
\hline P42 & Agreeableness & Likes to cooperate with others & 83.64 & 2 \\
\hline $\mathrm{P} 13$ & Conscientiousness & Is a reliable worker & 83.09 & 3 \\
\hline P 7 & Agreeableness & Is helpful and unselfish with others & 81.82 & 4 \\
\hline P 33 & Conscientiousness & Does things efficiently & 79.09 & 5 \\
\hline P 3 & Conscientiousness & Does a thorough job & 78.36 & 6 \\
\hline P 32 & Agreeableness & Is considerate and kind to almost everyone & 77.45 & 7 \\
\hline $\mathrm{P} 20$ & Openness & Has an active imagination & 76.00 & 8 \\
\hline P 36 & Extraversion & Is outgoing, sociable & 75.27 & 9 \\
\hline P 11 & Extraversion & Is full of energy & 75.27 & 10 \\
\hline P 17 & Agreeableness & Has a forgiving nature & 74.36 & 11 \\
\hline P 5 & Openness & Is original, comes up with new ideas & 72.18 & 12 \\
\hline P 1 & Extraversion & Is talkative & 72.00 & 13 \\
\hline P 15 & Openness & Is ingenious, a deep thinker & 71.82 & 14 \\
\hline P 30 & Openness & Values artistic, aesthetic experiences & 71.64 & 15 \\
\hline P 28 & Conscientiousness & Perseveres until the task is finished & 70.91 & 16 \\
\hline P 26 & Extraversion & Has an assertive personality & 70.73 & 17 \\
\hline P 16 & Extraversion & Generates a lot of enthusiasm & 70.36 & 18 \\
\hline P 10 & Openness & Is curious about many different things & 70.18 & 19 \\
\hline $\mathrm{P} 40$ & Openness & Likes to reflect, play with ideas & 69.45 & 20 \\
\hline P 35 & Openness & Prefers work that is routine & 68.73 & 21 \\
\hline P 38 & Conscientiousness & Makes plans and follows through with them & 67.45 & 22 \\
\hline P 29 & Neuroticism & Can be moody & 67.27 & 23 \\
\hline P 34 & Neuroticism & Remains calm in tense situations & 66.73 & 24 \\
\hline P9 & Neuroticism & Is relaxed, handles stress well & 65.27 & 25 \\
\hline P 23 & Conscientiousness & Tends to be lazy & 62.18 & 26 \\
\hline P 41 & Openness & Has few artistic interests & 62.00 & 27 \\
\hline P 14 & Neuroticism & Can be tense & 61.82 & 28 \\
\hline P 43 & Conscientiousness & Is easily distracted & 61.82 & 29 \\
\hline P 25 & Openness & Is inventive & 60.36 & 30 \\
\hline P 31 & Extraversion & Is sometimes shy, inhibited & 59.27 & 31 \\
\hline P 44 & Openness & Is sophisticated in art, music, or literature & 59.09 & 32 \\
\hline P 8 & Conscientiousness & Can be somewhat careless & 57.82 & 33 \\
\hline P 19 & Neuroticism & Worries a lot & 57.45 & 34 \\
\hline P 27 & Agreeableness & Can be cold and aloof & 56.18 & 35 \\
\hline P 39 & Neuroticism & Gets nervous easily & 56.00 & 36 \\
\hline P 24 & Neuroticism & Is emotionally stable, not easily upset & 55.09 & 37 \\
\hline P 21 & Extraversion & Tends to be quiet & 55.09 & 38 \\
\hline P 6 & Extraversion & Is reserved & 52.73 & 39 \\
\hline P 2 & Agreeableness & Tends to find faults with others & 51.64 & 40 \\
\hline P 37 & Agreeableness & Is sometimes rude to others & 50.00 & 41 \\
\hline $\mathrm{C} 18$ & Conscientiousness & Tends to be disorganized & 48.00 & 42 \\
\hline P 4 & Neuroticism & Is depressed, blue & 40.55 & 43 \\
\hline P 12 & Agreeableness & Starts quarrels with others & 40.18 & 44 \\
\hline
\end{tabular}

\subsection{Correlation Analysis}

The correlation between the responses of survey participants in relation to job satisfaction statements was calculated through SPSS statistical tool. The five job satisfaction statements 
were assigned JSF1 to JSF5 codes.

The correlation matrix of job satisfaction statements is shown in Table 4 which shows correlation results statistically significant with p-values lower than 0.01 and 0.05 .

Table 2. Correlation between job satisfaction statements

\begin{tabular}{|l|l|l|l|l|l|}
\hline & JSF1 & JSF2 & JSF3 & JSF4 & JSF5 \\
\hline JSF1-I am satisfied with my current job & 1 & & & & \\
\hline & $.786^{* *}$ & 1 & & & \\
JSF2-Mostly, I am excited about my job & $(.001)$ & $(.001)$ & & & \\
\hline & $-.524^{* *}$ & $-.555^{* *}$ & 1 & & \\
JSF3-Mostly, I am unexcited about my job & $(.000)$ & $(.001)$ & $(.001)$ & & \\
\hline & $.401^{* *}$ & $.416^{* *}$ & $-.214^{* *}$ & 1 & \\
JSF4-I enjoy my job most of the time & $(.001)$ & $(.000)$ & $(.007)$ & $(.001)$ & \\
\hline & $-.422^{* *}$ & $-.330^{* *}$ & $.421^{* *}$ & $-.197^{*}$ & 1 \\
JSF5-I really unlike my job & $(.000)$ & $(.000)$ & $(.000)$ & $(.035)$ & $(.001)$ \\
\hline
\end{tabular}

The relationship between job satisfaction and demographic variables was also found using correlation matrix. The correlation matrix in Table 3 displays significant relationships between job satisfaction and demographic variables.

Table 3. Link between job satisfaction and demographic variables

\begin{tabular}{|l|l|l|l|l|l|}
\hline & Gender & Age & Qualification & Tenure & Job Satisfaction \\
\hline Gender & 1 & & & & \\
\hline Age & $\begin{array}{l}.053 \\
(.615)\end{array}$ & 1 & & & \\
\hline Qualification & $\begin{array}{l}-.221^{*} \\
(.001) 3)\end{array}$ & $\begin{array}{l}-.554^{* *} \\
(.000)\end{array}$ & 1 & & \\
\hline Tenure & $.149^{*}$ & $.459^{* *}$ & $-.324^{* *}$ & 1 & \\
& $(.032)$ & $(.000)$ & $(.000)$ & & \\
\hline \multirow{2}{*}{ Job Satisfaction } & $-.221^{*}$ & $.237^{*}$ & -.101 & .062 & 1 \\
& $(.015)$ & $(.048)$ & $(.252)$ & $(.422)$ & \\
\hline
\end{tabular}

Table 3 shows statistically significant relationships between job satisfaction and demographic variables. The table shows that job satisfaction is negatively correlated with gender and it is positively correlated with age of the employees. This means that the job satisfaction level of employees declines with the passage of time. The statistically insignificant relationships are highlighted in the table which clearly shows that there are statistically insignificant 
correlations among job satisfaction, tenure, and qualification of the employees.

The relationship between job satisfaction and big five personality groups is found using correlation matrix to address first hypothesis which states that "Except Neuroticism, other individual personality characteristics of employees in retail sector are significantly correlated with job satisfaction". The correlation matrix in Table 4 displays significant relationships between job satisfaction and personality characteristics.

Table 4. Correlation between job satisfaction and personality groups

\begin{tabular}{|l|l|l|l|l|l|l|}
\hline $\begin{array}{l}\text { Personality } \\
\text { groups }\end{array}$ & JSF & Extraversion & Agreeableness & Conscientious & Neuroticism & Openness \\
\hline JSF & 1 & & & & & \\
\hline Extraversion & $.212^{* *}$ & 1 & & & & \\
\hline Agreeableness & $.612^{* *}$ & $.031^{* *}$ & 1 & & & \\
\hline Conscientious & $.172^{* *}$ & $.242^{* *}$ & $.162^{* *}$ & 1 & & \\
\hline Neuroticism & $-.169^{*}$ & $-.044^{*}$ & $.158^{* *}$ & $.088^{*}$ & 1 & \\
\hline Openness & $.011^{*}$ & $.342^{* *}$ & $-.020^{*}$ & $.431^{*}$ & $.343^{* *}$ & 1 \\
\hline
\end{tabular}

\section{Discussion}

\subsection{Job Satisfaction and Demographic Factors}

The findings of this study closely related to the findings from the literature. For example, in this study, the researcher found that regardless of gender difference, young people with ages between 18 and 30 works in the UK retail sector and they look happy and satisfied with their current jobs. But on the other hand, the survey results reveal that mostly undergraduate and GCSE diploma holders do jobs in the retail sector for the purpose to bear their educational and day-to-day expenses. During the survey, no candidate marked Mphil/PhD but a fair percentage of people i.e., 23\% selected postgraduate. This shows that people with high education also tend to work in the retail industry. This also relates to the indication of Bhutto et al. (2012) who found a significant relationship between education level and job satisfaction.

The results of this study uncover a high employee turnover in the UK retail industry as most of the survey participants i.e., 49\% marked their experience between 1 and 5 years. This means that a majority of young people work in the retail industry are students who work temporarily and then move if good jobs are offered. This fact is also highlighted by Scott et al. (2005) in their study by mentioning that people work in the retail industry only to earn money to bear their daily expenses.

The results of correlation analysis are interesting which state insignificant link between job satisfaction and education and also between job satisfaction and tenure. This in fact relates to the findings of Gurbuz (2011) who mention that there is no significant relationship between 
job satisfaction and education of an employee. But on the other hand, Scott et al. (2005) deny this fact and argue in the favor of a significant link of job satisfaction with employee's education and tenure.

\subsection{Job Satisfaction and Personality Traits}

The results of ranking of personality traits show that "Agreeableness" and "Conscientiousness" types of personalities are normally more satisfied from their jobs in the UK retail sector. This helps the researcher to resolve the myth that which personality factor of Big Five Factor model has high job satisfaction rate. With the best knowledge of the researcher, no study has been conducted in the past that attempt to find such details.

The impact of Big Five Personality characteristics of job satisfaction is explored by a number of researchers in the past and all are agreed that apart from neuroticism all personality group factors are positively associated with job satisfaction. The results of this study are also in line with the previous findings. For example, Judge et al. (2002) estimated a statistically significant correlation up to 0.25 between job satisfaction and extraversion and this is confirmed in this study with the correlation figure 0.212 . Similarly according to Mihalcea (2013), people with agreeableness traits achieve high job satisfaction compared to other personalities. This is also true in this study because the correlation between job satisfaction and agreeableness is maximum i.e., 0.612 .

The meta analysis of Judge et al. (2002) reveals that people with conscientiousness behaviour attain high job satisfaction level up to nearly 0.26 correlation. In this study, the researcher found 0.17 positive and statistically significant correlation between job satisfaction and conscientious. The opinion of experts about openness to experience is different in the literature of management. McCrae \& Allik (2012) mention that openness to experience is strongly associated with job satisfaction. In contrast, Judge et al. (2002) argue that openness to experience tends to have a weak relationship with job satisfaction. The survey results of this study are more close to the findings of Judge \& Colquitt (2004) because the calculated correlation is weak i.e., 0.11 between job satisfaction and openness to experience.

Finally, the association between job satisfaction and neuroticism is found negative in this study with a correlation value of -.0169. A number of researchers in the past reported negative correlation between neuroticism and job satisfaction where Judge et al. (2002), Lucas \& Dyrenforth (2008), and Tosi \& Pilati (2011) are prominent.

In this study, the researcher also attempts to find correlations between different personality groups to measure their association levels. The findings reveal that neuroticism is negatively associated with job satisfaction as well as with extraversion. But interestingly, it is positively correlated with other three personality groups i.e., Agreeableness, Conscientious, and Openness. On the other hand, openness to experience has a negative relationship with agreeableness which is true because a person with agreeableness trait cannot be open minded at all. 


\section{Conclusions}

It is concluded that people with the extravert personality trait secure managerial positions and are compatible with the working environment. Thus, they are fairly satisfied with their jobs and often proved as important assets for the company. The findings of primary research reveal that extraversion is significantly correlated with job satisfaction and other personality traits apart from Neuroticism. People with agreeableness personality characteristics are even more satisfied with their jobs and they are motivated by particular award schemes. The primary research findings in this study confirm the literature review findings that people with agreeableness traits usually achieve high job satisfaction compared to other personalities.

The employees with conscientiousness behavior achieve low job satisfaction when compared with extraversion and agreeableness but it achieves high job satisfaction in contrast to openness to experience. The similar results were obtained from the primary research but they slightly differ from the literature findings where few experts believe that openness to experience is strongly associated with job satisfaction. Lastly, neuroticism is somehow similar to extraversion in terms of human's neurological and physiological mechanisms. In contrast, people with neuroticism traits are not entitled to rewards due to their unstable emotions, lack of temperament, and sometimes aggressive behavior at work. The people with this personality trait are often dissatisfied with their jobs and therefore the association between job satisfaction and neuroticism is weak and depressing. Similar results obtained while conducting surveys in the UK retail industry where the correlation between job satisfaction level and neuroticism is found negative. Below are the correlations between job satisfaction and big five personality groups.

\begin{tabular}{|l|l|l|l|l|l|}
\hline & & Agreeableness & Conscientious & Neuroticism & Openness \\
\hline Job Satisfaction & $0.212^{* *}$ & $0.612^{* *}$ & $0.172^{* *}$ & $-0.169^{*}$ & $0.11^{*}$ \\
\hline
\end{tabular}

The above concluding remarks and findings from the primary research urge the researcher to accept the first hypothesis (H1) which demonstrates that "except Neuroticism, other individual personality characteristics of employees in the retail sector are significantly correlated with job satisfaction".

It is also concluded that a majority of young male and female students with 1 to 5 years of experience working temporarily in the UK retail industry to bear their regular expenses. It is also concluded that job satisfaction is based on employee demographics such as gender, age, education, and tenure. But the impact of these factors is different on job satisfaction. The gender and age are statistically significant with job satisfaction while education and tenure are insignificant. On the other hand, gender and education are negatively correlated with job satisfaction whereas age and tenure have a positive relationship with job satisfaction. Below are the correlations between job satisfaction and demographic variables of employees working in the retail sector. 


\begin{tabular}{|l|l|l|l|l|}
\hline & Gender & Age & Education & Tenure \\
\hline Job Satisfaction & $-0.221^{*}$ & $0.237^{*}$ & -0.101 & 0.062 \\
\hline
\end{tabular}

On the basis of the above fact, the researcher cannot accept second hypothesis (H2) which states that there is a significant relationship between job satisfaction and employee demographics. In fact, gender and age are statistically significant but education and tenure are insignificant.

It is also concluded from the ranking results that employees with 'Agreeableness' and "Conscientiousness" personalities are more successful in their careers and consequently they are more satisfied with their current jobs. This facilitates the researcher in resolving the myth that which personality factor of Big Five Factor model has higher job satisfaction rate. Overall, it can be said that personality traits and demographics have deep impact on job satisfaction. This is also true in case of employees working in the UK retail sector environment.

\section{References}

Ashton, M. C. (2013). Individual Differences and Personality (2nd ed.). New York: Academic Press.

Awadh, A. M., \& Ismail, W. K. W. (2012). The Impact of Personality Traits and Employee Work-Related Attitudes on Employee Performance with the Moderating Effect of Organizational Culture: The Case of Saudi Arabia. Asian Journal of Business and Management Sciences, 1(10), 108-127.

Bashir, M., Jianqiao, L., Jun, Z., Ghazanfar, F., \& Khan, M. M. (2011). The role of demographic factors in the relationship between high performance work system and job satisfaction: a multidimensional approach. International Journal of Business and Social Science, 2(18), 207-218.

Bhutto, N. A., Anwar, N., \& Khawaja, H. A. (2012). Relationship of Age, Gender, Tenure, Rank and Job Satisfaction-Empirical Evidence from Business Institute of Pakistan. International Journal of Contemporary Business Studies, 3(6), 15-27.

Broadbridge, A. M., Maxwell, G. A., \& Ogden, S. M. (2007). 13_2_30: Experiences, perceptions and expectations of retail employment for Generation Y. Career Development International, 12(6), 523-544. http://dx.doi.org/10.1108/13620430710822001

Bryman, A., \& Bell, E. (2007). Business Research Methods (2nd ed.). Oxford: Oxford University Press.

Capara, G. V., Schwartz, S., Capanna, C., Vecchione, M., \& Barberanelli, C. (2006). Personality and politics: values, traits, and political choice. Political Psychology, 27(1), 1-28. http://dx.doi.org/10.1111/j.1467-9221.2006.00447.x

Caprara, G. V., Vecchione, M., Alessandri, G., Gerbino, M., \& Barbaranelli, C. (2011). The 
contribution of personality traits and self-efficacy beliefs to academic achievement: a longitudinal study. The British Journal of Educational Psychology, 81(1), 78-96. http://dx.doi.org/10.1348/2044-8279.002004

Celia, B. R. (2012). Impact of Work Related Demographic Factors on Job Satisfaction of Teaching Staff in Self Financing Engineering Colleges. International Journal of Exclusive Management Research, 2(3), 2249-2585.

Doloi, H., Sawhney, A., Iyer, K. C., \& Rentala, S. (2011). Analysing factors affecting delays in Indian construction projects. International Journal of Project Management, 30, 479-489. http://dx.doi.org/10.1016/j.ijproman.2011.10.004

Eswaran, S., Islam, A., \& Yusuf, D. H. M. (2011). A Study of the Relationship between the Big Five Personality Dimensions and Job Involvement in a Foreign Based Financial Institution in Penang. International Business Research, 4(4), 164-175. http://dx.doi.org/10.5539/ibr.v4n4p164

Furnham, A., Eracleous, A., \& Chamorro-Premuzic, T. (2009). Personality, motivation and job satisfaction: Hertzberg meets the Big Five. Journal of Managerial Psychology, 24(8), 765-779. http://dx.doi.org/10.1108/02683940910996789

Gurbuz, A. (2011). An assessment on the effect of education level on the job satisfaction from the tourism sector point of view. Dogus University Journal, 8(1), 36-46.

Hsieh, Y. H. (2011). Empirical study on personality traits, job satisfaction, and reward system preferences. African Journal of Business Management, 5(12), 4983-4992.

Jackson, S. L. (2011). Research methods and statistics: A critical thinking approach (4th ed.). Stamford: Cengage Learning.

Judge, T. A., \& Colquitt, J. A. (2004). Organizational justice and stress: The mediating role of work-family conflict. Journal of Applied Psychology, 89(3), 395-404. http://dx.doi.org/10.1037/0021-9010.89.3.395

Judge, T. A., Heller, D., \& Mount, M. K. (2002). Five-factor model of personality and job satisfaction: A meta-analysis. Journal of Applied Psychology, 87, 530-541. http://dx.doi.org/10.1037/0021-9010.87.3.530

Kermani, Z. Z. (2013). A Study of the Linking Between Job Satisfaction and Customer Satisfaction: A Case Study of Iran Insurance; Kerman; Iran. Journal of Marketing Development and Competitiveness, 7(4), 104-109.

Kerr, B., \& McKay, R. (2013). Searching for Tomorrow's Innovators: Profiling Creative Adolescents. Creativity Research Journal, 21-32. http://dx.doi.org/10.1080/10400419.2013.752180

Kumar, K., \& Bakhshi, A. (2010). The five-factor model of personality and organisational commitment: Is there any relationship? Humanity and Social Sciences Journal, 5(1), 25-34.

La Sala, L., Skues, J., \& Grant, S. (2014). Personality Traits and Facebook Use: The 
Combined/Interactive Effect of Extraversion, Neuroticism and Conscientiousness. Social Networking, 3, 211-219. http://dx.doi.org/10.4236/sn.2014.35026

Lucas, R. E., Le, K., \& Dyrenforth, P. E. (2008). Explaining the extraversion/positive affect relation: Sociability cannot account for extraverts' greater happiness. Journal of Personality, 76, 385-414. http://dx.doi.org/10.1111/j.1467-6494.2008.00490.x

McCrae, R. R., \& Allik, J. (2012). The Five-Factor Model of Personality across Cultures. New York: Springer Science \& Business Media.

McDougall, W. (2016). Character and the Conduct of Life: Practical Psychology for Everyman. New York: Routledge.

Mihalcea, A. (2013). The Impact of Leader's Personality on Employees' Job Satisfaction. $\begin{array}{llll}\text { Procedia-Social and Behavioral } & \text { Sciences, } & \text { 78(13), }\end{array}$ http://dx.doi.org/10.1016/j.sbspro.2013.04.257

Millon, T., Meagher, S., Grossman, S., \& Ramnath, R. (2012). Personality Disorders in Modern Life (2nd ed.). New Jersey: John Wiley \& Sons.

Saunders, M., Lewis, P., \& Thornhill, A. (2009). Research methods for business students (5th ed.). New York: Pearson Education Limited.

Schultz, D., \& Schultz, S. E. (2015). Psychology and Work Today (10th ed.). New York: Routledge

Scott, M., Swortzel, K. A., \& Taylor, W. N. (2005). The Relationships between Selected Demographic Factors and the Level of Job Satisfaction of Extension Agents. Journal of Southern Agricultural Education Research, 55(1), 102-115. http://dx.doi.org/10.5032/jae.2005.03002

Shadel, W. G., Cervone, D., Niaura, R., \& Abrams, D. B. (2004). Investigating the big five personality factors and smoking: implications for assessment. Journal of Psychopathology and Behavioral Assessment, 26(3), 185-191. http://dx.doi.org/10.1023/B:JOBA.0000022111.13381.0c

Sutin, A. R., Costa, P. T., Miech, R., \& Eaton, W. W. (2009). Personality and career success: concurrent and longitudinal relations. European Journal of Personality, 23(2), 71-84, http://dx.doi.org/10.1002/per.704

Tosi, H. L., \& Pilati, M. (2011). Managing Organizational Behavior: Individuals, Teams, Organization and Management. Cheltenham \& Camberley: Edward Elgar Publishing.

Vogt, L., \& Laher, S. (2009). The five factor model of personality and individualism/collectivism in South Africa: an exploratory study. Psychology in Society, 1015-6046.

Whysall, P., Foster, C., \& Harris, L. (2009). Job dissatisfaction among retail employees: a study of three leading UK retailers. International Review of Retail, Distribution and Consumer Research, 19(2), 179-188. http://dx.doi.org/10.1080/09593960903109519 


\section{Macrothink}

Business and Management Horizons

ISSN 2326-0297 2016, Vol. 4, No. 1

Zitny, P., \& Halama, P. (2011). Self-esteem, locus of control and personality traits as predictors of sensitivity to injustice. Studia Psychologica, 53(1), 27-40.

\section{Copyright Disclaimer}

Copyright for this article is retained by the author(s), with first publication rights granted to the journal.

This is an open-access article distributed under the terms and conditions of the Creative Commons Attribution license (http://creativecommons.org/licenses/by/3.0/). 